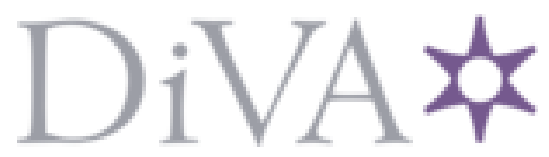

http://www.diva-portal.org

\title{
Preprint
}

This is the submitted version of a paper published in Aging \& Mental Health.

Citation for the original published paper (version of record):

Bratt, A S., Stenström, U., Rennemark, M. (2016)

The Role of Neuroticism and Conscientiousness on Mortality Risk in Older Adults After Child and Spouse Bereavement.

Aging \& Mental Health, 20(6): 559-566

http://dx.doi.org/10.1080/13607863.2015.1031638

Access to the published version may require subscription.

N.B. When citing this work, cite the original published paper.

This is an Author's Original Manuscript of an article published by Taylor \& Francis in "Aging \& Mental Health" on [09 Apr 2015] available online at http://www.tandfonline.com/ $10.1080 / 13607863.2015 .1031638$

Permanent link to this version:

http://urn.kb.se/resolve?urn=urn:nbn:se:lnu:diva-42899 


\section{The Role of Neuroticism and Conscientiousness on Mortality Risk in Older Adults After Child and Spouse Bereavement}

Objective: Bereavement effects on mortality risk were investigated in 1150 randomly selected participants, aged 60-104, in the Swedish National Study of Aging and Care.

Method: Cox proportional hazards models, controlling for age, gender, functional ability, the personality traits neuroticism and conscientiousness as well as time since the latest loss were used to predict mortality risk.

Results: Having lost a child, spouse or both child and spouse did not predict mortality risk. An indirect link between bereavement and mortality was found showing for each year since loss the mortality risk decreased by about $1 \%$. Neuroticism, but not conscientiousness, was associated with mortality risk, with a small-effect size.

Conclusions: The different bereavements did not predict mortality risk while an indirect link was found showing that mortality risk decreased with time.

\section{Introduction}

Dying from a broken heart is a metaphor for the intense emotional pain when losing a loved one but also a description of a physical condition known as "Tako-tsubo cardiomyopathy" (broken heart syndrome) (Prasad, Lerman, \& Rihal, 2008). This condition, with clinical symptoms similar to a heart attack, shows how emotional and stressful events can cause severe and painful physical conditions (Pilgrim \& Wyss, 2008). The loss of a child is considered to be the most stressful life event one can encounter followed by the loss of a spouse (Cleiren, Diekstra, Kerkhof et al., 1994; Miller \& Rahe, 1997). Higher risk of mortality has been found after child as well as spousal loss (Stroebe, Schut, \& Stroebe, 2007). The majority of studies have shown spousal-bereaved men are at higher mortality risk than spousal-bereaved women (Moon, Kondo, Glymour et al., 2011), while child-bereaved women are at higher risk than child-bereaved men (Stroebe et al., 2007). In the meta-analysis of Moon et al. (2011), comparing married same-sex counterparts, spousal-bereaved men had a 23\% higher mortality risk while the spousal-bereaved women did not have a significantly higher mortality risk. Another review (Stroebe et al., 2007) showed a 17-21\% higher mortality risk in spousal-bereaved men and a 6-17\% higher mortality risk in women. Two studies, one in Sweden (Rostila, Saarela, \& Kawachi, 2012) and the other in Denmark (Li, Precht, Mortensen et al., 2003), found that child-bereaved women had a higher risk of mortality from all causes compared to non-bereaved mothers (31\% vs. 43\% respectively). In the Swedish study, the corresponding mortality risk was $21 \%$ higher for child-bereaved men compared to 
non-bereaved fathers. In the Danish sample, child-bereaved men were at a higher risk of mortality from unnatural causes only in the first three years of follow-up.

Time since the loss is described as one of the most influential factors to adjustment after bereavement (Lund, Caserta, \& Dimond, 1993). A 41\% higher mortality risk has been found (Moon et al., 2011) during the first six months after spouse bereavement, which decreased to 14\% after six months. Another finding (Stroebe et al., 2007) showed a two-fold increase in mortality risk during the second half of the first year of spousal bereavement: the risk were restricted to the first year for women while for spousal-bereaved men the mortality risk decreased after 24 months but remained high for years after the loss. In bereaved parents the risk of mortality is highest in the first year after the loss (Li et al., 2003) but may stay elevated up to thirty-five years (Harper, 2011).

Besides the disruptive feelings associated with losing a child or spouse, the bereavement includes the loss of both emotional and practical support given by the deceased (Lund et al., 1993; Smith, Nunley, Kerr et al., 2011) and they may be faced with the need to handle duties that their partner used to be responsible for, such as preparing food or managing the economy (Lund et al., 1993). Having several such shortcomings regarding functional ability have been found to be associated with higher mortality risk in a sample of adults, 65 years or older (Fried, Kronmal, Newman et al., 1998). In addition, a decline in functional ability has been seen among older adults who had lost a child or a spouse (d'Epinay, Cavalli, \& Guillet, 2009), an effect that decreased by time. However, there is a gap in knowledge for the effects of functioning in older adults bereaved of both a child and a spouse.

When coping with the challenges of bereavement, individual personality characteristics can be either beneficial or detrimental to adjustment (Hansson \& Stroebe, 2007). The relationship between personality and mortality risk after bereavement has not been sufficiently investigated while the link between personality and mortality is well studied. Especially the trait neuroticism, characterized by anxiety, hostility, self-consciousness and impulsiveness has been found to be associated with an elevated mortality risk (Mroczek, Spiro III, \& Turiano, 2009). Some indications, however, show that high neuroticism also can be a protective mortality factor (Weiss \& Costa, 2005). The personality trait conscientiousness, described as being organised, reliable, punctual and self-disciplined, is found to be protective in relation to mortality (Weiss \& Costa, 2005; Terracciano, Löckenhoff, Zonderman et al., 2008). One prospective study focusing on the effect of personality on mortality risk after conjugal bereavement (Taga, Friedman, \& Martin, 2009) showed that spousal loss did not predict mortality either for women or for men. In that study, 
conscientiousness was found to be a protective survival factor. Neuroticism, however, was not associated with mortality risk except for the widowed men for whom it was found to be a protective factor. No studies, to the best of our knowledge, have explored the influence of personality in relation to child- as well as both child-spouse-bereavement effects on mortality.

In conclusion, most often both spousal and child bereavement is described as being associated with higher mortality risk. Child-bereaved women are at higher risk than childbereaved men while spousal-bereaved men seem to be at higher risk than spousal-bereaved women. The mortality risk is highest in the first year after both child and spousal loss and then it decreases. Being high in neuroticism seems mostly to be related to higher mortality risk while conscientiousness, on the other hand, is associated to lower mortality risk. The influence of personality in relation to bereavement effects on mortality including child or both child and spouse loss is, as far as we know, not yet explored. The aim of this study is to investigate the relationship between different bereavements and mortality and to consider the impact of gender differences, neuroticism and conscientiousness as well as the influence of functional ability and time since the latest loss. The main focus is on the loss of both child and spouse.

\section{Method}

\section{Participants and Procedure}

The Swedish National Study of Aging and Care (SNAC) is a longitudinal and interdisciplinary study conducted in four areas in Sweden of which this sample was collected from Blekinge (SNAC-B). SNAC-B received ethical permission from the Faculty of Medicine at Lund University (LU 605-00, LU 744-00). The study design has been described in earlier studies of SNAC (Lagergren, Fratiglioni, Hallberg et al., 2004). An invitation to join the study was sent to a total of 2312 randomly selected individuals by mail and 1402 responders (61 \%) agreed to participate. Forty participants, about one percent, died before the study started. The individuals who did not respond by mail were contacted again by telephone and the reasons for not wanting to participate were registered. The reasons mentioned by the 870 individuals ( $\approx 38 \%$ ) who declined to participate were: lack of interest $(83 \%)$ and impaired health (10\%), while the remaining subjects (7\%) could not be reached by the research staff. All respondents lived in Karlskrona, a town of about 64000 inhabitants similar to other towns in Sweden in terms of distribution of age, gender and functional ability, for further details see Lagergren et al. (2004). Ten age cohorts were selected with the following age distribution: 60 years (n=191), 66, ( $n=206), 72$ ( $n=177), 78$ ( $n=166), 81$ ( $n=155), 84$ (n=200), $87(n=150), 90$ 
( $n=99), 93(n=40)$ and $96(n=18)$. The data were collected between 2001 and 2003 and included medical examinations, cognitive tests and survey questions. Informed consent was obtained in writing from the participants during the first session. The survey was conducted in two sessions of three hours each and during the first session the participants received the survey questions. The respondents answered the questions at home between sessions. The research staff made a home visit to those older adults who were unable to come to the research centre. In order to avoid missing data, the examining teams supported those participants who had difficulties filling out the survey. Date of death was regularly collected for those participants who passed away, the latest case in August 2013.

\section{Measures}

A Swedish version of the 60-item NEO Five-Factor Inventory (NEO-FFI) (Costa Jr \& McCrae, 1989) was used to measure personality and has been further discussed in other studies of SNAC (Dahl, Allwood, Rennemark et al., 2010). Each scale consists of 12 items with a five-point likert response format with alternatives from 1 (do not agree at all) to 5 (agree completely). The higher the total score (max 60) on a personality-factor the more the individual is characterised with that specific trait. In the present study the NEO-FFI traits of interest were neuroticism and conscientiousness. Using Cronbach's coefficient alpha, the internal consistency in the present study was for Neuroticism, $\alpha=.81$ and Conscientiousness, $\alpha=.82$ which can be compared to Neuroticism, $\alpha=.73$ and Conscientiousness, $\alpha=.73$ in the Changing Lives of Older Couples-study (Pai \& Carr, 2010).

Bereavement status, collected from a life-event scale and developed for the SNAC study included 25 negative life events relevant for the aging population, such as family bereavements, relational problems and financial worries. The bereavement questions included loss of parents, child, grandchild, spouse and best friend but only child and spouse loss were selected for the purpose of this study. Bereavement status was collected at baseline, 20012003.

Functional ability was measured by the Instrumental Activities of Daily Living (IADL) self-rating scale, (Lawton \& Brody, 1969) which has demonstrated good internal consistence with a reported alpha coefficient of 85 (Graf, 2008). Cronbach's Alpha for the present sample was .82. This instrument, designed to assess independent living skills, consists of eight domains of function such as food preparation, housekeeping and the ability to handle finances. The scale, scoring from zero (low function, dependent) to eight (high function, independent). Healthy aged populations usually score 6 and above (Graf, 2008). 


\section{Plan of Analysis}

Statistical analyses were calculated by SPSS version 22. First, descriptive statistics were conducted followed by comparison between men and women using Independent sample ttests. One-way between-groups analyses of variance with post-hoc tests using Tukey HSD test were performed for comparison between the bereaved and non-bereaved groups. To analyse the proportion of dead vs. living individuals by gender as well as bereavement status Chi-square tests were used. Cox proportional hazards regression analyses were conducted to explore the risk of mortality. In the first model, the impact of the different bereavement categories per se regarding mortality was investigated. The second model explored gender differences in the bereaved groups. In the last two models the association between gender, bereavement status and personality in relation to mortality were explored. In Cox proportional hazards regression analysis the parameter estimates log-hazard ratios shown in B. Since the effects of log-hazards are hard to interpret the Exp (B) or hazard-ratios (HRs) with 95\% confidence intervals are shown. HRs represent the degree of change in mortality risk for a unit change in a predictor. HR below 1.0 means decreased risk and greater than 1.0 increased risk. If a variable is dichotomous $(0,1)$ then HR below 1.0 indicates that group 1 is at lower risk than group 0 . HR of 1.0 indicates no difference in risk between the groups and HR greater than 1.0 indicates increased risk for group 1 as compared to group 0.

\section{Results}

The total sample ( $\mathrm{N}=1402)$ consisted of 817 women (58.3 \%) and 585 men (41.7\%). There were 362 (25.8\%) individuals who had lost their spouse, 69 (4.9\%) had lost a child and 84 (6.0\%) had lost both spouse and child. A total of 635 (45.3\%) individuals had not experienced any of the above-mentioned losses. Missing data, regarding loss of child or spouse, was registered from 252 individuals. The most frequent reason for not answering the loss variables was non-registration $(n=230)$, health reasons $(n=15)$ or reluctance to answer questions about negative events ( $n=7)$. The majority of the participants where either married ( $n=677,48.3 \%)$ or widowed ( $n=463,33 \%)$. There were 89 (6.3\%) individuals who had never been married and 80 (5.7\%) respondents who were divorced. In Table 1 descriptive statistics for the total sample are shown as well as differences between men and women measured by Independent sample t-tests. The results showed that the women were older and had higher scores on neuroticism. There were no gender differences regarding conscientiousness and functional ability. 
Insert Table 1

One-way between-groups analyses of variance with post-hoc tests using Tukey HSD test were conducted for comparisons between the different groups (child, spouse, child-spouse and nonbereaved) as shown in Table 2. The non-bereaved group was youngest, had lower neuroticism and higher conscientiousness scores. The child-spouse group was oldest and had the lowest functional ability. The child-bereaved group had experienced a longer time since their loss compared to the other bereaved groups.

Insert Table 2

A total number of 732 (52.2\%) individuals died between 10 January 2001 and 24 August 2013, 417 (57\%) women and 315 (43 \%) men. The age of death varied between 60 and 104 years, mean age 87.60 , (women $M=89.22$ years, men $M=85.44$ ). At the time of the latest follow up 670 (47.8\%) individuals were living, 401 (60 \%) women and 269 (40\%) men. The living participants were between 70 and 103 years, mean age 80.98 (women $\mathrm{M=81.66}$ years and men $\mathrm{M}=79.96)$. When comparing the proportion of living vs. dead, the spouse-bereaved and child-spouse-bereaved groups were overrepresented in the deceased group compared to the non-bereaved (spouse bereaved $n=225$, expected count 172 and child-spouse bereaved $n=60$, expected count 40 while child bereaved $n=30$, expected count 32.7 , non-bereaved individuals, $n=230$, expected count 300$), \chi^{2}(3, n=1150)=83.3, \mathrm{p}<.000$, Cramer's V $=.27$. According to Cohen's criteria (Cohen, 1988) Cramer's V $=.30$ is regarded as a medium effect size. When comparing the women only, the same pattern was found with spouse-bereaved and child-spouse-bereaved women being overrepresented in the deceased group, while the childbereaved women and the non-bereaved women were not (spouse bereaved $n=173$ expected count 128 and the child-spouse bereaved $n=45$, expected count 28 while child bereaved $n=11$, expected count 18 and non-bereaved women $n=65$, expected count 120), $\chi^{2}(3$, $\mathrm{n}=662)=97.09, \mathrm{p}<.000$, Cramer's $\mathrm{V}=.38$. Finally, among the men all the bereaved men were overrepresented in the deceased group (child-bereaved men $n=19$, expected count 15 , spousebereaved men $n=52$, expected count 39 and child-spouse-bereaved men $n=15$, expected count 10 compared to non-bereaved men $n=165$, expected count 187), $\chi^{2}(3, n=488)=21.80, \mathrm{p}<$ .000 , Cramer's V = .21.

Cox Proportional Hazard regression analysis was used to assess if child, spouse or child-spouse bereavement predicts mortality (Table 3). Due to missing values on either of the 
variables described above, (se Table 1), there were 976 individuals included in the analyses of survival (child bereaved $n=59$, spouse bereaved, $n=293$, child-spouse bereaved, $n=69$ ). The result in the first model showed that age, functional ability (IADL), gender and neuroticism significantly affected the hazard function. The results show that increasing age with one year decreases the HRs by $11.4 \%$. A one point higher score in functional ability lowers the risk of dying by $13.2 \%$. The risk of dying is higher for men by about $81 \%$ compared with women. For each increase in the neuroticism score the mortality risk increases by $1.8 \%$. The bereavement statuses had no significant relation to mortality nor had conscientiousness and time since the loss.

Insert Table 3

Model 2 investigated whether there was a difference in risk of mortality between bereaved men and women. The results showed an interaction effect, with child-bereaved men having a 94.8 \% higher mortality risk compared to child-bereaved women. No gender differences were found in the other bereaved groups. Time since the latest loss showed an effect on the HR: for each year since the loss, the risk of mortality decreased by $0.8 \%$. In model 3, the results showed that child-bereaved men had a 2.7 \% higher mortality risk than child-bereaved women for each increase in the neuroticism score. No gender differences were found in spouse or child-spouse bereaved men and women. Time since loss had a significant effect on the HR: for each year since the loss the risk of mortality decreased by $0.8 \%$. Finally, in the last Cox regression analysis in model 4, gender differences in the bereaved groups in relation to conscientiousness were investigated. An increased mortality risk for child-bereaved men by $1.7 \%$ compared to child-bereaved women for each increase in the conscientiousness score was found.

\section{Discussion}

The risk of losing a close relative or having experienced several losses is higher among older individuals (Hansson \& Stroebe, 2007) and is a trauma assumed to shorten one's life. The present study is, as far as we know, the first study to investigate the impact of losses on mortality regarding the loss of either a spouse or a child or the loss of both a child and a spouse.

Although other studies have shown an overall increased mortality after spouse (Stroebe et al., 2007; Moon et al., 2011) or child loss (Li et al., 2003; Hendrickson, 2009; Harper, 
2011; Rostila et al., 2012; Espinosa \& Evans, 2013), and that the bivariate analysis in the present study showed that the spouse-bereaved as well as child-spouse-bereaved participants were overrepresented in the deceased group, the survival analyses, controlling for age, gender, functional ability, neuroticism and conscientiousness as well as time since loss, obtained no such relationship. However, an indirect link between mortality risk and bereavement was found showing that for each year since the loss the mortality risk decreased, which is in accordance with other studies (Li et al., 2003; Moon et al., 2011; Rostila et al., 2012). The long-term follow-up may have smoothed out more immediate risks associated with the loss.

In the total sample neuroticism was associated with higher risk of mortality in the present study, yet with a small-effect size. Despite the fact that the elderly had higher scores of neuroticism ( $M=27.65$, SD 6.86 vs. $M=15.77$, SD 7.47), as compared to the norms of neuroticism of the NEO Five-Factor Inventory (McCrae \& Costa Jr, 2004), the longevity of this sample is high. Even though conscientiousness was not found to be a protective factor in relation to mortality, the longevity may be due the participants' high levels of conscientiousness ( $M=45.28$, SD 5.79 as compared to the norms $M=33.48$, SD 6.36).

No gender differences were found except in the child-bereaved group, where an increase in neuroticism as well conscientiousness for the men was related to increased mortality risk compared to the child-bereaved women. The bivariate analyses showed that fewer women in the child-bereaved group than expected had died both compared to the childbereaved men and the spouse-bereaved and child-spouse-bereaved women. The majority of earlier studies have shown, however, child-bereaved women being at higher mortality risk than non-bereaved mothers as well as child-bereaved men (Li et al., 2003; Hendrickson, 2009; Rostila et al., 2012; Espinosa \& Evans, 2013). Younger child-bereaved women have been found to be at greater risk of mortality than middle-aged child-bereaved women ( $\mathrm{Li}$ et al., 2003). Thus, in contrast to our sample, consisting of only older individuals, most of the studies on mortality of bereaved parents include above all younger and middle-aged parents (Li et al., 2003; Rostila et al., 2012; Espinosa \& Evans, 2013). Different samples may be one reason for not revealing higher mortality risk in this sample and survival effects (Aldwin, Yancura, \& Boeninger, 2007) another, since bereaved individuals who are more vulnerable do not reach older age.

As shown in this study, having lost both a child and spouse did not increase the mortality risk. A loss of a close relative is a pervasive experience causing painful feelings parallel with a change in everyday life. The child-spouse group had the lowest functional ability of all participants, which could be related to their higher age. Another explanation 
might be that bereavement, per se, had affected their ability to manage everyday tasks - an assumption in accordance with earlier findings (d'Epinay et al., 2009) showing that losing a spouse or child can be associated with a deterioration in functional ability. A high functional ability has been found to be associated with better long-term bereavement outcome after spousal bereavement (Lund et al., 1993). It will be important for future research to follow-up the underlying causes regarding the finding that those bereaved of both a child and a spouse had lower functional ability.

\section{Strength and limitations}

The SNAC-B study of older adults has a number of important strengths, including longitudinal assessments in a randomly selected sample consisting of different age cohorts. A number of important factors relevant for mortality are included in the analyses of the present study, information that studies from national registers do not have access to. In large samples, showing higher mortality in bereaved individuals (Li et al., 2003; Harper, 2011; Rostila et al., 2012; Espinosa \& Evans, 2013) the reason may be because other important factors have influenced the results than the loss of a loved one. The result that the different bereavements did not predict mortality is somewhat in line with the findings from the meta-analysis of spousal bereavement by Moon et al. (2011), controlling for more covariates than age and gender, showing no significant effect of spouse bereavement on mortality either for women or for men.

One limitation of the study is the lack of information about the proportion of bereaved and non-bereaved in the missing group. How this affected the results of the study is unknown. Some of the individuals who did not answer the bereavement questions explained that they did not want to talk about negative events but the majority gave no explanation. Resistance to respond can for some participants have been due to avoidance of negative feelings associated with losses of loved ones. Missing data on one or more variables resulted in a reduction of participants in the survival analysis. This decreased the power, which should be taken into account when the results are interpreted.

Another limitation is that bereavement status was only asked for at baseline and because of that some participants have most likely experienced more losses before they passed away. Thus, the SNAC-B data set does not include those who have had more recent experiences of the death of a loved one during the period from baseline. To address this issue, future research within the SNAC-B could be improved as to this aspect of the design and include questions about losses of loved ones in the follow-up sessions. Nevertheless, it is still a problem that the 
findings will be based only on older adults who have survived until they are interviewed at time for follow-up.

\section{Conclusions and implications for future research}

As far as we know this is the first study to investigate how different familial bereavements in a lifetime perspective affect mortality in older age. In a sample of 976 older adults of which more than half of the group were bereaved, the results of the multivariate analysis indicated that having lost a child, spouse or both child and spouse in a lifetime perspective, did not predict mortality in older age. This finding is important to acknowledge. The overall conclusion from the majority of earlier research is that losing a child or spouse is associated with higher mortality risk. However, the majority of these studies do not include important covariates. The conception, per se, that loss of a loved one is associated with a risk of dying from a broken heart, may have a negative effect on bereaved individuals. Lazarus and Folkman (Lazarus \& Folkman, 1984) described, in their cognitive stress theory, that both the appraisal of the stressful event, as well as the resources of the individual to handle it, are important factors for the outcome. One study (Keller, Litzelman, Wisk et al., 2012) that confirm the assumption by Lazarus and Folkman, investigated how different beliefs about stress affect mortality. The results showed that there was a $43 \%$ higher mortality risk in individuals who reported high levels of stress in combination with the belief that stress has a negative effect of health. However, individuals who had as high levels of stress but believed that stress did not have a negative effect on health, showed a lower mortality risk, even lower than those individuals who were not stressed at all. Is the perception "dying from a broken heart”, per se, negative for health and survival in bereaved individuals? The association between bereaved individuals' appraisal of the loss in relation to their own abilities to cope and how this affects outcome needs further exploration. Those individuals who have survived the loss of loved ones and reach older age may be especially resilient and future research needs to focus on what factors favour resilience in bereaved older adults. Is it possible to clarify what characterizes those who, despite difficulties and setbacks, have the strength to cope and survive for a long time?

Yet, the finding that mortality risk decreased in time, irrespectively of type of bereavement (child, spouse or both child and spouse), shows an indirect link between higher mortality in bereaved individuals. Therefore, the mortality risk should be taken seriously and needs to be further investigated. Based on the results of the present study, more attention should be given to explore mortality in older child-bereaved men. Another important focus, in 
future studies, is to explore whether having lost both a child and a spouse lower functional ability in older adults. Furthermore, studies are needed that systematically examines what clinical and practical support should be given to older bereaved adults, especially in the first year after the death. When meeting newly bereaved in health care, one important aspect might be to strengthen their ability to handle the difficult emotions associated with the loss.

Teaching bereaved how to interpret bodily sensations and how to regulate difficult emotions have in psychotherapy been found to prevent a further escalation of emotions and promote coping with life difficulties (Leahy, Tirch, \& Napolitano, 2011). 


\section{References}

Aldwin, C., Yancura, L., \& Boeninger, D. (2007). Coping, Health, and Aging. In C. M. Aldwin, C. L. Park \& A. Spiro III (Eds.), Handbook of health psychology and aging (1st ed., pp. 210-226). New York: The Guilford Press

Cleiren, M., Diekstra, R. F., Kerkhof, A. J., et al. (1994). Mode of death and kinship in bereavement: focusing on "who" rather than "how". Crisis, 15(1), 22-36.

Cohen, J. (1988). Statistical Power Analysis for the Behavioral Sciences (A. Press Ed. 2nd ed.). New York: Routledge.

Costa Jr, P. T., \& McCrae, R. R. (1989). The Neo-PI/Neo-FFI manual supplement: Odessa, FL: Psychological Assessment Resources.

d'Epinay, C. J. L., Cavalli, S., \& Guillet, L. A. (2009). Bereavement in very old age: impact on health and relationships of the loss of a spouse, a child, a sibling, or a close friend. OMEGA--Journal of Death and Dying, 60(4), 301-325. doi: 10.2190/OM.60.4.a

Dahl, M., Allwood, C. M., Rennemark, M., et al. (2010). The relation between personality and the realism in confidence judgements in older adults. European Journal of Ageing, 7(4), 283-291. doi: 10.1007/s10433-010-0164-2

Espinosa, J., \& Evans, W. N. (2013). Maternal bereavement: The heightened mortality of mothers after the death of a child. Economics \& Human Biology, 11(3), 371-381. doi: /10.1016/j.ehb.2012.06.002

Fried, L. P., Kronmal, R. A., Newman, A. B., et al. (1998). Risk factors for 5-year mortality in older adults: the Cardiovascular Health Study. Jama, 279(8), 585-592. doi: 10.1001/jama.279.8.585

Graf, C. (2008). The Lawton instrumental activities of daily living scale. AJN The American Journal of Nursing, 108(4), 52-62.

Hansson, R. O., \& Stroebe, M. S. (Eds.). (2007). Bereavement in late life: Coping, adaptation, and developmental influences (1st ed.). Washington: American Psychological Association.

Harper, M. (2011). Coping and Outcomes Following Parental Bereavement. (Bibliographies Theses Non-fiction), University of Stirling. Available from EBSCOhost edsble database.

Hendrickson, K. C. (2009). Morbidity, mortality, and parental grief: a review of the literature on the relationship between the death of a child and the subsequent health of parents. Palliative \& Supportive Care, 7(1), 109-119. doi: 10.1017/S1478951509000133

Keller, A., Litzelman, K., Wisk, L. E., et al. (2012). Does the perception that stress affects health matter? The association with health and mortality. Health Psychology, 31(5), 677. doi: 10.1037/a0026743.supp

Lagergren, M., Fratiglioni, L., Hallberg, I. R., et al. (2004). A longitudinal study integrating population, care and social services data. The Swedish National study on Aging and 
Care (SNAC). Aging Clinical and Experimental Research, 16(2), 158-168. doi: 10.1007/BF03324546

Lawton, M. P., \& Brody, E. M. (1969). Assessment of older people: Self-maintaining and instrumental activities of daily living. The Gerontologist, 9(3, Pt 1), 179-186. doi: 10.1093/geront/9.3_Part_1.179

Lazarus, \& Folkman. (1984). Stress, appraisal, and coping. New York: Springer.

Leahy, R. L., Tirch, D., \& Napolitano, L. A. (2011). Emotion regulation in psychotherapy: A practitioner's guide. New York: Guilford Press.

Li, J., Precht, D. H., Mortensen, P. B., et al. (2003). Mortality in parents after death of a child in Denmark: a nationwide follow-up study. Lancet, 361(9355), 363-367. doi: 10.1016/S0140-6736(03)12387-2

Lund, D. A., Caserta, M. S., \& Dimond, M. F. (1993). The Course of Spousal Bereavement in Later Life. In M. Stroebe, W. Stroebe \& R. Hansson (Eds.), Handbook of bereavement: Theory, research, and intervention (pp. 240-254). New York: Cambridge University Press

McCrae, R. R., \& Costa Jr, P. T. (2004). A contemplated revision of the NEO Five-Factor Inventory. Personality and Individual Differences, 36(3), 587-596. doi: 10.1016/S0191-8869(03)00118-1

Miller, M. A., \& Rahe, R. H. (1997). Life changes scaling for the 1990s. Journal of Psychosomatic Research, 43(3), 279-292. doi: 10.1016/S0022-3999(97)00118-9

Moon, J., Kondo, N., Glymour, M., et al. (2011). Widowhood and Mortality: A MetaAnalysis. PLoS ONE, 6(8). doi: 10.1371/journal.pone.0023465

Mroczek, D. K., Spiro III, A., \& Turiano, N. A. (2009). Do health behaviors explain the effect of neuroticism on mortality? Longitudinal findings from the VA Normative Aging Study. Journal of Research in Personality, 43(4), 653-659. doi: 10.1016/j.jrp.2009.03.016

Pai, M., \& Carr, D. (2010). Do Personality Traits Moderate the Effect of Late-Life Spousal Loss on Psychological Distress? Journal of health and social behavior, 51(2), 183199. doi: $10.1177 / 0022146510368933$

Pilgrim, T. M., \& Wyss, T. R. (2008). Takotsubo cardiomyopathy or transient left ventricular apical ballooning syndrome: A systematic review. International journal of cardiology, 124(3), 283-292. doi: 10.1016/j.ijcard.2007.07.002

Prasad, A., Lerman, A., \& Rihal, C. S. (2008). Apical ballooning syndrome (Tako-Tsubo or stress cardiomyopathy): A mimic of acute myocardial infarction. American heart journal, 155(3), 408-417. doi: 10.1016/j.ahj.2007.11.008 
Rostila, M., Saarela, J., \& Kawachi, I. (2012). Mortality in parents following the death of a child: a nationwide follow-up study from Sweden. Journal of Epidemiology \& Community Health, 66(10), 927-933. doi: 10.1136/jech-2011-200339

Smith, M. E., Nunley, B. L., Kerr, P. L., et al. (2011). Elders' Experiences of the Death of an Adult Child. Issues in Mental Health Nursing, 32(9), 568-574. doi: 10.3109/01612840.2011.576802

Stroebe, M., Schut, H., \& Stroebe, W. (2007). Health outcomes of bereavment. Lancet, 370, 1960-1973. doi: 10.1016/S0140-6736(07)61816-9

Taga, K. A., Friedman, H. S., \& Martin, L. R. (2009). Early Personality Traits as Predictors of Mortality Risk Following Conjugal Bereavement. Journal of personality, 77(3), 669690. doi: 10.1017/S0033291700049084

Terracciano, A., Löckenhoff, C. E., Zonderman, A. B., et al. (2008). Personality predictors of longevity: Activity, Emotional stability, and Conscientiousness. Psychosomatic medicine, 70(6), 621-627. doi: 10.1097/PSY.0b013e31817b9371

Weiss, A., \& Costa, P. T. (2005). Domain and Facet Personality Predictors of All-Cause Mortality Among Medicare Patients Aged 65 to 100. Psychosomatic medicine, 67(5), 724-733. doi: 10.1097/01.psy.0000181272.58103.18 
Table 1 Descriptive statistics of the sample

\begin{tabular}{llllllll}
\hline Variable & $\mathrm{N}$ & Minimum & Maximum & $\begin{array}{l}\text { Total } \\
\text { Mean }\end{array}$ & SD & Mean women (SD) & Mean men (SD) \\
\hline Age & 1402 & 60 & 96 & 76.68 & 10.19 & $77.64(10.2)^{* * *}$ & $75.4(10.0)$ \\
Neuroticism & 1099 & 12 & 49 & 27.65 & 6.86 & $29.05(6.9) * * *$ & $25.88(6.4)$ \\
Conscientiousness & 1065 & 21 & 60 & 45.28 & 5.79 & $45.03(5.7)$ & $45.59(5.9)$ \\
IADL & 1256 & 0 & 8 & 6.24 & 2.13 & $6.25(2.2)$ & $6.34(1.9)$ \\
\hline
\end{tabular}

Note: ${ }^{* * *} \mathrm{p}<.001$ gender differences, Independent samples t-tests. $\mathrm{N}=$ included in analyses 
Table 2 One-way between-groups ANOVA with post-hoc tests

\begin{tabular}{|c|c|c|c|c|c|c|c|c|c|c|c|c|c|}
\hline \multirow[t]{3}{*}{ Variables } & \multicolumn{2}{|c|}{ Child-bereaved } & \multicolumn{4}{|c|}{$\underline{\text { Child-spouse-bereaved }}$} & \multicolumn{2}{|c|}{ Spouse-bereaved } & \multicolumn{4}{|c|}{$\underline{\text { Non-bereaved }}$} & \multirow{2}{*}{$\begin{array}{l}\text { p-value } \\
\text { Differences } \\
\text { between } \\
\text { groups }\end{array}$} \\
\hline & $\begin{array}{l}\text { Mean } \\
\text { women } \\
\text { (SD) }\end{array}$ & $\begin{array}{l}\text { Mean men } \\
\text { (SD) }\end{array}$ & $\begin{array}{l}\text { Total } \\
\text { mean } \\
\text { (SD) }\end{array}$ & $\begin{array}{l}\text { Mean } \\
\text { women } \\
\text { (SD) }\end{array}$ & $\begin{array}{l}\text { Mean men } \\
\text { (SD) }\end{array}$ & $\begin{array}{l}\text { Total mean } \\
\text { (SD) }\end{array}$ & $\begin{array}{l}\text { Mean } \\
\text { women } \\
\text { (SD) }\end{array}$ & $\begin{array}{l}\text { Mean men } \\
\text { (SD) }\end{array}$ & $\begin{array}{l}\text { Total mean } \\
\text { (SD) }\end{array}$ & $\begin{array}{l}\text { Mean } \\
\text { women } \\
\text { (SD) }\end{array}$ & $\begin{array}{l}\text { Mean men } \\
\text { (SD) }\end{array}$ & $\begin{array}{l}\text { Total mean } \\
\text { (SD) }\end{array}$ & \\
\hline & $n=40$ & $n=29$ & $n=69$ & $n=64$ & $n=20$ & $n=84$ & $n=287$ & $n=75$ & $n=362$ & $n=271$ & $n=364$ & $n=635$ & \\
\hline Age & $\begin{array}{l}72.15 \\
(8.5)\end{array}$ & $78.83(9.3)$ & $\begin{array}{l}74.96 \\
(9.0)\end{array}$ & $84.14(6.5)$ & $84.45(6.2)$ & $84.21(6.4)$ & $80.75(8.3)$ & $81.84(8.2)$ & $80.98(8.3)$ & $69.93(8.4)$ & $72.23(9.3)$ & $71.25(9.0)$ & $* * *$ \\
\hline IADL & $\begin{array}{l}7.14 \\
(1.3)\end{array}$ & $6.40(1.6)$ & $\begin{array}{l}6.85 \\
(1.5)\end{array}$ & $5.56(2.0)$ & $5.81(2.0)$ & $5.74(1.90)$ & $6.44(1.9)$ & $6.0(1.9)$ & $6.42(1.8)$ & $7.23(9.3)$ & $6.72(1.5)$ & $6.95(1.4)$ & $* * *$ \\
\hline Neuroticism & $\begin{array}{l}29.77 \\
(5.7)\end{array}$ & $26.36(6.0)$ & $\begin{array}{l}28.23 \\
(5.9)\end{array}$ & $28.73(7.5)$ & $24.32(5.2)$ & $28.17(6.7)$ & $29.11(7.5)$ & $27.40(6.3)$ & $29.15(7.1)$ & $27.94(6.7)$ & $25.45(6.6)$ & $26.57(6.7)$ & $* * *$ \\
\hline Conscientiousness & $\begin{array}{l}45.94 \\
(5.4)\end{array}$ & $46.50(4.7)$ & $\begin{array}{l}46.18 \\
(5.1)\end{array}$ & $43.41(5.4)$ & $46.00(3.8)$ & $44.20(5.1)$ & $44.61(5.8)$ & $44.93(5.2)$ & $44.68(5.7)$ & $45.76(5.5)$ & $45.80(6.1)$ & $45.78(5.9)$ & * \\
\hline $\begin{array}{l}\text { Time since loss } \\
\text { (years) }\end{array}$ & $\begin{array}{l}31.90 \\
(16.9)\end{array}$ & $\begin{array}{l}30.16 \\
(18.0)\end{array}$ & $\begin{array}{l}31.19 \\
(17.3)\end{array}$ & $\begin{array}{l}14.52 \\
(13.8)\end{array}$ & $\begin{array}{l}10.56 \\
(12.5)\end{array}$ & $\begin{array}{l}13.57 \\
(13.5)\end{array}$ & $\begin{array}{l}15.38 \\
(12.2)\end{array}$ & $\begin{array}{l}14.02 \\
(10.2)\end{array}$ & $\begin{array}{l}15.10 \\
(11.8)\end{array}$ & & & & $* * *$ \\
\hline
\end{tabular}

Note. One-way between groups analyses of variance with post-hoc tests. ${ }^{* * *} \mathrm{p}<.001^{* *} \mathrm{p}<.01^{*} \mathrm{p}<.05$ 
Table 3 Cox regression analyses on mortality

\begin{tabular}{|c|c|c|c|c|c|c|c|c|}
\hline \multirow{2}{*}{$\begin{array}{l}\text { Model } 1 \\
\text { Variables }\end{array}$} & \multirow[b]{2}{*}{ B } & \multirow[b]{2}{*}{$\mathrm{SE}$} & \multirow[b]{2}{*}{ Wald } & \multirow[b]{2}{*}{ Df } & \multirow[b]{2}{*}{ Sig. } & \multirow[b]{2}{*}{ HR } & \multicolumn{2}{|c|}{ 95\% CI for HR } \\
\hline & & & & & & & Lower & Upper \\
\hline Age & -.121 & .013 & 91.709 & 1 & .000 & .886 & .864 & .908 \\
\hline IADL & -.141 & .035 & 16.701 & 1 & .000 & .868 & .812 & .929 \\
\hline Gender & .593 & .123 & 23.098 & 1 & .000 & 1.810 & 1.421 & 2.306 \\
\hline Child loss & .177 & .300 & .349 & 1 & .555 & 1.193 & .663 & 2.147 \\
\hline Spouse loss & .001 & .160 & .000 & 1 & .996 & 1.001 & .732 & 1.368 \\
\hline Child-spouse loss & -.210 & .227 & .858 & 1 & .354 & .810 & .520 & 1.264 \\
\hline Time since loss & -.004 & .006 & .424 & 1 & .435 & .996 & .986 & 1.006 \\
\hline Neuroticism & .018 & .009 & 3.871 & 1 & .049 & 1.018 & 1.000 & 1.037 \\
\hline Conscientiousness & -.008 & .011 & .511 & 1 & .475 & .992 & .972 & 1.013 \\
\hline \multicolumn{7}{|l|}{ Model 2} & \multicolumn{2}{|c|}{ 95\% CI for HR } \\
\hline Variables & B & SE & Wald & Df & Sig. & HR & Lower & Upper \\
\hline Age & -.138 & .011 & 163.056 & 1 & .000 & .871 & .853 & .890 \\
\hline IADL & -.203 & .027 & 55.672 & 1 & .000 & .817 & .774 & .861 \\
\hline Gender X Child loss & .667 & .250 & 7.116 & 1 & .008 & 1.948 & 1.193 & 3.179 \\
\hline Gender X Spouse loss & .129 & .162 & .634 & 1 & .426 & 1.137 & .829 & 1.562 \\
\hline Gender X Child-spouse loss & .269 & .285 & .890 & 1 & .345 & 1.309 & .748 & 2.289 \\
\hline Time since loss & -.008 & .004 & 4.841 & 1 & .028 & .992 & .984 & .999 \\
\hline \multicolumn{7}{|l|}{ Model 3} & \multicolumn{2}{|c|}{ 95\% CI for HR } \\
\hline Variables & $\mathrm{B}$ & SE & Wald & Df & Sig. & HR & Lower & Upper \\
\hline Age & -.138 & .011 & 157.846 & 1 & .000 & .871 & .853 & .890 \\
\hline IADL & -.202 & .027 & 54.347 & 1 & .000 & .817 & .774 & .862 \\
\hline Neuroticism $\mathrm{X}$ gender $\mathrm{X}$ child loss & .026 & .010 & 7.666 & 1 & .006 & 1.027 & 1.008 & 1.046 \\
\hline Neuroticism $\mathrm{X}$ gender $\mathrm{X}$ spouse loss & .003 & .006 & .287 & 1 & .592 & 1.003 & .991 & 1.016 \\
\hline $\begin{array}{l}\text { Neuroticism X gender X child- } \\
\text { spouse loss }\end{array}$ & .016 & .012 & 1.723 & 1 & .189 & 1.016 & .992 & 1.040 \\
\hline Time since loss & -.008 & .004 & 4.142 & 1 & .042 & .992 & .985 & 1.000 \\
\hline \multicolumn{7}{|l|}{ Model 4} & \multicolumn{2}{|c|}{ 95\% CI for HR } \\
\hline Variables & $\mathrm{B}$ & SE & Wald & Df & Sig. & HR & Lower & Upper \\
\hline Age & -.135 & .011 & 152.963 & 1 & .000 & .874 & .855 & .893 \\
\hline IADL & -.198 & .028 & 51.705 & 1 & .000 & .820 & .777 & .866 \\
\hline $\begin{array}{l}\text { Conscientiousness X gender X child } \\
\text { loss }\end{array}$ & .017 & .006 & 8.220 & 1 & .004 & 1.017 & 1.005 & 1.030 \\
\hline $\begin{array}{l}\text { Conscientiousness X gender X } \\
\text { spouse loss }\end{array}$ & .004 & .004 & .770 & 1 & .380 & 1.004 & .996 & 1.012 \\
\hline $\begin{array}{l}\text { Conscientiousness X gender X } \\
\text { child-spouse loss }\end{array}$ & .004 & .007 & .356 & 1 & .551 & 1.004 & .991 & 1.018 \\
\hline Time since loss & -.009 & .004 & 4.888 & 1 & .027 & .991 & .984 & .999 \\
\hline
\end{tabular}

Note: Gender $0=$ woman, $1=$ man. Child loss $0=$ no child loss, $1=$ have lost a child, Spouse loss $0=$ no spouse loss, $1=$ have lost a spouse, Child-spouse $0=$ no child or spouse loss, $1=$ have lost both child and spouse.

Hazard ratio (HR) is risk ratios. 